\title{
1. The central banking century: an introduction to institutional central banking Peter Conti-Brown
}

Historians are at the early stages of making sense of what historians call the long twentieth century, dating roughly from the late nineteenth century through the global financial crisis of 2008. It has been an extraordinary period, a time consumed by war, hot and cold; terrorism, in the skies and on the ground; successive revolutions in travel and communications; and the depths of multiple depressions and the heights of unparalleled prosperity. Trying to make sense of this history over the longue durée will be a consuming project for the foreseeable future.

It is not an exaggeration, however, to put central banks at the center of the dizzying highs and exhausting lows. In many ways, the twentieth century was the century that central bankers built, for better and for worse. The advent of the modern, bureaucratised, mostly publicly controlled central bank was born not in seventeenth century Sweden, but in twentieth century America. And the concept of 'central bank independence', a defining concept, has echoes in earlier eras, but didn't come into its maturity until well into the twentieth century. Central banks' behavior during the 2008 crisis represents an apotheosis for this vision, not an exception.

The open question, then, isn't whether central banks and central bankers were at the center of things in the twentieth century. It is whether they will survive, intact, the twenty-first. Reports of populist uprisings representing the end of the technocratic consensus of the 1990s are greatly exaggerated; the populist enthusiasms that stand so starkly against the vision of central banking as an autonomous enterprise are hardly stable. But the fall of 2008 brought seismic shifts in the central banking landscape, both inside and outside those banks.

This volume represents an effort by a diverse set of scholars to make sense of where central banks stand at the end of that long twentieth century. It is, my co-editor Rosa Lastra and I believe, the most diverse set of disciplinary commitments brought to bear on the questions of what central banks are, have been, and might become. The study of central banks is a venerable one, albeit largely dominated by practitioners, academic economists, and, if we are honest, fringe conspiracists. This volume represents something different. Some of the most interesting contributions come from the first two categoriesCharles Goodhart and Andy Haldane, for example, bridging those two gaps. But we have also included historians, legal scholars, political scientists, an accountant and an anthropologist. This multidisciplinary effort was self-conscious. We viewed the puzzle of central banking as one that can only be clarified from multiple angles. It is the proverbial elephant, the disciplines of the proverbial blind men trying to describe what they feel. If this volume is successful, it is because we have tried to take a broader view of the elephant than is normally possible through just one disciplinary lens. (Although, to be clear, we didn't include the fringe conspiracists.) 


\section{Research handbook on central banking}

The central idea behind the volume is that central banks are institutions in multiple senses of the word. It is an institution as that term is used by economists like Douglass North, as 'humanly devised constraints that structure political, economic and social interaction' that 'consist of both informal constraints (sanctions, taboos, customs, traditions, and codes of conduct), and formal rules (constitutions, laws, property rights).' ${ }^{1}$ It is a set of rules, laws, norms that arise to respond to the identified needs of a nation or system. But they are also institutions as organizations, a set of buildings, a culture, governed by laws but also subject to non-legal and extra-legal devices that shape who they are and where they will go. The institutions of central banking, then, are about both the US Federal Reserve System and broad thinking about price stability, the Bank of England and reactions to financial panic.

To get at this institutional framework, we divide the volume in two. The first half deals with individual case studies; the second with broad themes that will affect most if not all central banks in the twenty-first century. Our canvas of the world is broad and nearly comprehensive. I give an overview of the highly historically contingent nature of central banking in the United States, focusing on the uneven institutional evolution of the US Federal Reserve. Forrest Capie and Geoffrey Wood provide a capsule history of the Bank of England and highlight a theme we see throughout the volume: the institutions of central banking did not arrive fully formed, but have evolved unevenly through the years and, in the Bank of England's case, the centuries. Hideki Kanda and Toshiaki Yamanaka take us through the Bank of Japan (BOJ), long considered one of the least independent of central banks, but one that has not suffered from runaway inflation as models of central bank independence might suggest. Indeed, the Japanese experience has been just the opposite: Japan has struggled with historically low levels of inflation. Kanda and Yamanaka's treatment of the Bank of Japan illustrates what we hope to accomplish in this volume. It is a historical, legal and institutional treatment that explores, accessibly, how an important institution like the BOJ has changed over time. Raj Bhala provides a similar overview of the Reserve Bank of India.

Juliet Johnson, a political scientist, opens the hood on a fascinating set of institutions: central banks in post-Soviet Russia. Johnson explores another theme that is prominent in the volume: how do politically dominated central banks function as anything other than governmental functionaries? The answer, for the Bank of Russia, is reputational: even if Vladimir Putin (or the many other governments without strong independent central banks) dominates the political scene, there is potential for some kind of autonomy to develop.

Given its prominence, we have two chapters on the People's Bank of China (PBOC). Zhongfei Zhou describes the challenges and opportunities for the PBOC with the development of the Shanghai Free Trade Zone, a kind of credible commitment that functions similarly to governmental commitments to independent central banks. The PBOC's own Xiangmin Liu provides a deeper, more historical account of the PBOC, emphasizing again - as with Conti-Brown and Capie and Wood - the evolutionary nature of central banking change.

1 North, Douglass C. 'Institutions'. The Journal of Economic Perspectives 5, no 1 (1991), 97-112. 
In separate chapters, Rene Smits and Chiara Zilioli and Antonio Riso describe the European Central Bank (ECB), focusing variously on the ECB's legal structure and how it has sought to thread the needle between technocracy and accountability during the crisis of the twenty-first century. Chris Adam, Andy Berg, Rafael Portillo and Filiz Unsal take on most of an entire continent to describe central banking institutions in sub-Saharan Africa. Adam et al. focus especially on the success story of sub-Saharan Africa via inflation targeting, while also discussing what happens when governments seek not to trim the sails of central banks, but to add to their functions.

Harold James, an eminent historian of central banking, takes a look into the German Bundesbank. The choice to focus on the German example may seem out of place in a volume about central banking in the twenty-first century, given the dominance of the ECB in Europe. But as James shows, the institutional solution of the Bundesbank continues to resonate in contemporary discussions of European central banking.

Sheelagh McCracken and Frank Decker provide a similar historical and institutional overview of central banking in Australia and New Zealand, a fascinating story about commonwealth institutions finding their footing in the shadow of the Bank of England, and then as innovators that set the standard for the rest of the world. The two percent inflation target, for example, is a New Zealand export. Luis Jacome of the International Monetary Fund (IMF) concludes part I by providing a detailed overview of central banking in Latin America, demonstrating another key reason for this geographically-focused effort: there is much that we see in the development of these institutions around the globe, but also much that is deeply local.

The second half of the book develops more concretely some of the themes addressed in the first. It begins with Rosa Lastra exploring perhaps the defining question in central banking, central bank independence. This elusive concept has dominated discussions of central banking since roughly the 1980s, but, as Lastra explains, that conceptual understanding rests on an incomplete foundation. And in any case, the 2008 financial crisis and its policy aftermath have introduced challenges to an old framework that was dominated by the concern to prevent political mismanagement of inflation.

Anthropologist David Bholat and accountant Robin Darbyshire write about an often overlooked but still essential component of central banking practice: accounting. Accounting can seem to be a dry concept for low-level employees, but Bholat and Darbyshire demonstrate that accounting is at the core of understanding central banks, their work, and the political relationships that guide them. The authors also put the discussion of 'auditing' central banks into a more rigorous conversation than is customary for that perennial topic.

This handbook is global in scope and ambition, but often comparative. Robert Kahn and Ellen Meade introduce 'international coordination' as a reality, both as a policy challenge and a policy tool for major central banks. In this nuanced chapter, Kahn and Meade discuss how diplomacy and coordination differ, and then take readers on a guided tour through recent central banking history, discussing how much central banks rely on each other in accomplishing most of their major goals.

Most of this chapter is focused on central banks; Andy Haldane, chief economist of the Bank of England, refocuses our attention on central bankers. Haldane's chapter brings into conversation behavioral economics and monetary policy, two threads in economics that don't often have much to say to each other. Exploring the central banker 


\section{Research handbook on central banking}

decision-making processes - including their limitations-helps us unpack exactly how central bankers will confront their challenges, old and new.

A key component of central banking practice, arguably since the late eighteenth century and certainly throughout the twentieth century, is central banks' role not only in regulating monetary policy but in supervising banks. Kern Alexander and Rosa Lastra discuss this ever-changing concept to explain how central banks can and should engage in bank supervision, and how supervision can facilitate and interfere with the institutions' other mandates.

The financial crisis of 2008 looms large over this volume, and rightly so. The crisis changed so much about how we think about central banks and how central banks think about themselves. Perhaps most importantly, the post-crisis monetary response was, to use a term of art, 'unconventional'. Claudio Borio and Anna Zabai, both of the Bank for International Settlements, provide the most thorough, empirical account of unconventional monetary policy of which I am aware. In their treatment, we learn that unconventional monetary policy has been largely effective, a view that counters some of central banks' leading critics. But we also learn that the benefits of these unconventional policies are unlikely to remain and should be, as a result, used only in emergencies.

The next two chapters, on payment systems by Benjamin Geva and on digital currencies by Max Raskin and David Yermack, touch on another core issue: how money functions through the global system. Geva covers the legal architecture of central banks in supervising the payment system, while Raskin and Yermack dig deeply into what the future may hold at the intersection of currency and technology. Saule Omarova takes a deep dive into financial stability and systemic risk regulation, a central banking mission at the core of the nineteenth-century model that became key again after the financial crisis. Omarova approaches the question by looking at competing conceptions of financial stability reform, especially focusing on reforming the structure of the financial industry versus the more bureaucratic approach taken in the US and EU.

Charles Goodhart, the dean of central banking scholars, explores macroprudential regulation, as distinct from systemic risk regulation. Goodhart gives a detailed account to answer four related questions: why did macroprudential regulation attain its near ubiquitous status in discussions of central banking, what macroprudential regulation actually means, who should be in charge of it, and how has this been accomplished in recent history. As is typical of Goodhart's work, the chapter is both innovative and accessible, providing a new take on an important issue that will engage experts and newcomers alike.

Christine Kaufmann and Rolf Weber discuss what they take as a tension with central bank independence: transparency. Central banks have not had a reputation for transparency through much of their history, although this has slowly been changing for many (though they have not always received credit for this). Kaufmann and Weber argue that transparency is essential to the functioning of central banks, despite the challenges that transparency can bring.

Paul Tucker, former Deputy Governor of the Bank of England, concludes the book by summarizing his influential views on central banks as lenders of last resort, a question he knows well as a scholar and practitioner. Tucker argues that the key problem for central banks as lenders of last resort is about delegation and legitimacy, a thorny reality that has focused the minds of central bankers the world over in the aftermath of the 2008 crisis.

Research handbooks are meant to be snapshots of a zeitgeist, the state of the research 
art for those who will be joining the conversation midstream. This book aims at that important tradition, but it is also different than this tradition. While research is summarized, it is not a collection of literature reviews. Sometimes the work presented comes from other publications, but for the most part the essays ahead are original, theoretical, conceptual, historical and empirical work. As a result, while the spirit of 2017 permeates the volume, the chapters are aiming at something more enduring than this. Central banks are experiencing a generational transition. These curious institutions, at the intersection of government and markets, dominated economic policy-making in the long twentieth century. It is still too early to predict with confidence the direction that a long twentyfirst century will take, but there is little doubt that central banks will play a dominant, if ever-changing, role. Research like that presented and summarized in this volume will help guide that debate.

A note of thanks to the Bank of England, the Wharton School of the University of Pennsylvania, and Queen Mary, University of London for their logistical support in gathering these scholars, and to Laura Mann at Edward Elgar for her patience in guiding the book's long incubation through to publication.

Let me conclude, too, with a personal note of thanks. Rosa María Lastra has become, through this project so much more than a collaborator. As one can imagine, editing a group of authors this diverse-from so many countries and disciplinary backgrounds, at various stages in their careers and active with their own busy schedules - could have been a laborious chore. It wasn't, in part because of the caliber of authors we have recruited. But the lion's share of the credit belongs to Rosa, my mentor and friend. It is rare that someone of her professional stature maintains a deep sense of humanity, but Rosa is a rare person. I count it a singular privilege to have undertaken this project at her invitation and will treasure the friendship for decades ahead.

Philadelphia, PA, June 2017 